Research article

\title{
Medication persistence over 2 years of follow-up in a cohort of early rheumatoid arthritis patients: associated factors and relationship with disease activity and with disability
}

\author{
Virginia Pascual-Ramos ${ }^{1}$, Irazú Contreras-Yáñez ${ }^{1}$, Antonio R Villa ${ }^{2}$, Javier Cabiedes ${ }^{1}$ and \\ Marina Rull-Gabayet ${ }^{1}$
}

\begin{abstract}
1Department of Immunology and Rheumatology, Instituto Nacional de Ciencias Médicas y Nutrición Salvador Zubirán, Vasco de Quiroga 15-Colonia Sección XVI-Tlalpan, México City, 14000, México

${ }^{2}$ Clinic Epidemiology Unit, Instituto Nacional de Ciencias Médicas y Nutrición Salvador Zubirán, Vasco de Quiroga 15-Colonia Sección XVI-Tlalpan, México City, 14000, México
\end{abstract}

Corresponding author: Virginia Pascual-Ramos, virtichu@lycos.com

Received: 1 Aug 2008 Revisions requested: 19 Sep 2008 Revisions received: 19 Nov 2008 Accepted: 19 Feb 2009 Published: 19 Feb 2009

Arthritis Research \& Therapy 2009, 11:R26 (doi:10.1186/ar2620)

This article is online at: http://arthritis-research.com/content/11/1/R26

(c) 2009 Pascual-Ramos et al.; licensee BioMed Central Ltd.

This is an open access article distributed under the terms of the Creative Commons Attribution License (http://creativecommons.org/licenses/by/2.0), which permits unrestricted use, distribution, and reproduction in any medium, provided the original work is properly cited.

\begin{abstract}
Introduction Aggressive treatment with disease-modifying antirheumatic drugs (DMARDs) plays a major role in improving early rheumatoid arthritis (RA) patient outcomes. Persistence and adherence with medication occurs variably (20\% to $70 \%)$. The objectives of the study were to determine medication persistence (MP) in early RA patients over 13 consecutive visits each 2 months apart, to investigate the relationship between MP and disease activity, disability and structural damage, and to identify baseline prognosticators.

Methods Charts from 75 patients of an early RA cohort were reviewed. At each visit, a rheumatologist interviewed patients regarding therapy, scored disease activity with the 28-joint disease activity score (DAS28) and disability with the health assessment questionnaire ( $\mathrm{HAQ}$ ), and recorded comorbidities and treatment. A complete medical history was obtained at baseline. MP was defined as the duration of time from initiation to discontinuation of at least one DMARD and/or corticosteroids for at least 1 week and was reported as a dichotomous variable at consecutive evaluations. Structural damage was defined by detection of new erosions on radiography. Descriptive statistics, Student's $t$ test, the chi-squared test, and logistic regression analyses were used.

Results The proportion of MP patients decreased from $98 \%$ at 2 months to $34 \%$ at 2 years. MP patients $(n=32)$ had similar DAS28 to non-MP patients $(n=53)$ at initial visits, lower DAS28 and greater DAS28 improvements at follow-ups $(P \leq 0.05$ at visits $4,6,7$ and 9$)$ and reached sustained remission $(\geq 3$ consecutive visits with DAS28 < 2.6) more frequently $(82.8 \%$ versus $46.5 \%, P=0.003)$ and earlier $(7.7 \pm 4.6$ versus $13.6 \pm$ 5.7 months, $P=0.001$ ) than non-MP patients. MP patients had similar baseline HAQ scores, but lower HAQ scores at followup $(P \leq 0.05$ at visits $3,5,6,7,9,10$ and 13$)$. More non-MP patients developed erosive disease than MP patients $(26.8 \%$ versus $17.9 \%, P=0.56)$. Older age at baseline was associated with therapy discontinuation (odds ratio $=1.1,95 \%$ confidence interval $=1.007$ to $1.103, P=0.02$ ).

Conclusions Discontinuation of DMARDs was frequent and progressive in an early RA cohort. Patients with persistence on therapy were younger, had lower disease activity and disability during follow-up, and reached sustained remission more frequently and earlier than patients without it. MP should intentionally be evaluated during follow-up of early RA patients, as it seems to play a major role in outcome.
\end{abstract}

\section{Introduction}

Rheumatoid arthritis (RA) is a chronic inflammatory disease that may result in significant disability, morbidity and increased mortality [1]. In recent years, earlier aggressive treatment with disease-modifying drugs (DMARDs) has been shown to play a major role in improving patient outcomes. Those benefits will be achieved only if patients follow prescribed treatment regimens reasonably closely. 
Both adherence and compliance are words commonly used to describe how patients take their medication. Traditionally, adherence to therapy has been defined as 'the number of patients continuing treatment with a particular drug prescribed by their health care provider, regardless of the clinical response' [2,3]. Guidance regarding the meaning of compliance (adherence) and persistence has been proposed recently [4]. Accordingly, medication compliance (synonym adherence) is defined as 'the extent to which a patient acts according to the prescribe interval and dose of a dosing regimen' and medication persistence is defined as 'the duration of time from initiation to discontinuation of therapy' [4].

Compliance to and persistence on medication may be monitored through different methods, direct and indirect, each one with particular advantages and disadvantages [2,5]. No method is considered the gold standard. Patient self-reports are simple, inexpensive and the most useful method in the clinical setting $[6,7]$, although higher rates of adherence/persistence have been reported when patient self-reports are used for evaluation [5].

Adherence rates are typically higher among patients with acute conditions as compared with those patients with chronic conditions. Persistence of adherence among patients with chronic conditions is disappointedly low and drops dramatically after the first 6 months of therapy [8-10]. Efforts had been made to develop a questionnaire to investigate patient compliance and persistence with antirheumatic drugs [11-13], but few studies have examined the topic in chronic inflammatory rheumatic conditions - the majority of these studies focused on RA treatment. In those studies, different definitions of adherence and persistence have been used and different populations and medications evaluated, thus limiting any conclusions. The current literature, however, suggests that nonadherence to and nonpersistence on DMARD therapy is a substantial problem, ranging in occurrence from $20 \%$ to $70 \%$ [10,14-23].

Many factors have been related to patient's medication behavior in RA patients, including younger age [16,21,23], male sex $[20,21]$, belonging to an ethnic minority [17], lower education [17], side effects [17], availability of financial resources and social support $[18,23]$, medication-taking behavior and beliefs [19], increased disability [20], better perceived health status at the beginning [10], poor quality of contact with health professionals [20], poor personal knowledge about the disease and its treatment [20], comorbidity [23] and the class of DMARDs $[10,15,22]$.

Compliance and persistence with prescribed medication regimens (and placebo regimens) predict better outcomes. Collecting adherence and persistence data from patients is considered an essential part of clinical trials.
By contrast, poor compliance and nonpersistence with medication contribute to substantial worsening of disease and death, and increase healthcare costs [2].

We report our experience with persistence on DMARDs and corticosteroids evaluated through patient-physician structured interviews, during 2 years of follow-up of an early RA cohort of patients. The aims of the study were to determine persistence on DMARDs and corticosteroids over 13 consecutive visits each 2 months apart in a cohort of early RA patients, to investigate the relationship between persistence on therapy and disease activity, to investigate the relationship between persistence on therapy and both disability and structural damage, and to identify whether any baseline factors are associated with nonpersistence on medication.

\section{Materials and methods \\ Setting and study population}

The Instituto Nacional de Ciencias Médicas y Nutrición Salvador-Zubirán is a referral centre for Rheumatic Diseases in México City. In February 2004, an early arthritis clinic was established. Patients with disease duration of less than 1 year and nonspecific rheumatic diagnosis at initial evaluation but with RA attended the clinic. As part of the standard care provided, patients were evaluated at baseline and every 2 months by the same rheumatologist.

For the present report, we included data for all patients who attended the clinic for at least 24 months (13 consecutive evaluations scheduled) up to March 2008: 70 patients completed 2-year follow-up; additionally, three patients were lost to follow-up before visit 3 , one before visit 8 and another patient before visit 13. Their data available up to the last observation were also included in the analysis. As persistence on therapy was evaluated from the second visit we excluded from the analysis four additional patients who were lost to follow-up after baseline evaluation.

\section{Clinical evaluations}

Standard baseline and follow-up evaluations included, at baseline, a complete demographic and medical history obtained by face-to-face interview, a rheumatic evaluation that assessed 66 swollen joint counts and 68 tender joint counts, and a physician global assessment of disease activity on a 100 $\mathrm{mm}$ visual analogue scale. Before the medical evaluation, a Hispanic version of the health assessment questionnaire (HAQ) [24] and two $100 \mathrm{~mm}$ visual analogue scales, one for pain and one for overall disease activity, were completed by patients. Laboratory investigations included, at minimum, determination of rheumatoid factor and C-reactive protein serum levels (both by nephelometry), a second-generation ELISA for antibodies to cyclic citrullinated peptides and the erythrocyte sedimentation rate by the Westergren method. Disease activity scores were calculated using the 28 -joint disease activity score (DAS28) [25]. 
For the follow-up evaluations, the $\mathrm{HAQ}$, the $100 \mathrm{~mm}$ visual analogue scale for pain, the $100 \mathrm{~mm}$ visual analogue scale for overall disease activity and the physician global assessment of disease activity on a $100 \mathrm{~mm}$ visual analogue scale were completed by patients and the physician, who additionally performed 66 swollen joint counts and 68 tender joint counts and scored the DAS28. The erythrocyte sedimentation rate and Creactive protein measurements were determined.

Information concerning comorbidities was established by record review, based on physician diagnosis; in addition, when a patient was given treatment for a specific diagnosis not recorded on the charts (for instance, antihypertensive therapy), the corresponding section was updated. Counted comorbidities were: arterial pulmonary hypertension, arterial systemic hypertension, asthma, cardiovascular disease, diabetes mellitus, end-stage renal disease, epilepsy, glaucoma, heart block, hepatic cirrhosis, hepatitis virus B infection, hepatitis virus $\mathrm{C}$ infection, hydrocephaly, hyperlipidemia, major depression, obesity, osteoarthritis, osteoporosis, psoriasis, pulmonary fibrosis, thyroid disorder and vitiligo.

At every visit the same rheumatologist performed a predefined interview regarding prescriptions. Patients were directed to refer to the name(s), dose(s) and schedule(s) of the drug(s) (DMARDs, corticosteroids and other) they had been taking since the last visit (2 months apart), initially spontaneously and if necessary directly. Patients were then asked about any missing/incorrect medication, dose and/or schedule since the previous visit; emphasis was placed on DMARDs and corticosteroids. The number of days of missing medication was also recorded. The rheumatologist compared the last prescription and actual treatment; if inconsistencies were found, they were solved.

Data were collected in standardized formats.

\section{Radiography}

Digitized images of radiographs of the hands and feet (postero-anterior and oblique views) were scheduled at baseline, at 1-year and at 2-year follow-up, and were read in chronological order by a radiologist and a rheumatologist. RA was classified as erosive disease (at least one cortical bone defect) or nonerosive disease, once consensus was reached.

\section{Treatment}

Treatment was recorded in standardized formats, including the use of corticosteroids (yes/no), the use of DMARDs (yes/no), the number and name(s) of DMARDs/patient and the treatment prescribed for comorbidities. Records included previous treatment (during the month prior to baseline evaluation) prescribed by physicians who referred patients to the clinic, baseline treatment prescribed by the rheumatologist in charge of the clinic at first evaluation, and treatment prescribed at each follow-up visit.
At baseline and consecutive visits, adverse events were recorded as part of the standard care provided. Treatment modifications because of adverse events were not considered as nonadherence/nonpersistence when indicated by a physician.

\section{Definitions}

Nonpersistence with medication was defined as the duration of time from initiation to discontinuation of DMARDs and/or corticosteroids of at least 7 consecutive days. Regarding methotrexate, at least one weekly missing dose was considered to meet the nonpersistence definition. Nonpersistence with therapy was evaluated from the second visit and was defined by an independent observer according to the information recorded on the charts.

Sustained remission was defined at last visit, as three or more consecutive visits each 2 months apart with a DAS28 below 2.6.

\section{Ethics}

Patients agreed to enter the Early Arthritis Clinic and approved clinical and radiological assessments. Treatment was prescribed by the rheumatologist in charged of the Early Arthritis Clinic according to patient and disease characteristics. The study was approved by the Institution Review Board. Written informed consent was obtained from all participating patients.

\section{Statistics}

By definition, persistence is reported as a continuous variable in terms of the number of days for which therapy was available, although it may also be reported as a dichotomous variable measured at the end of a predefined time period [4]. Accordingly, data are presented as the number (\%) of patients being persistent (or nonpersistent) at every consecutive visit.

Descriptive statistics, Student's $t$ test and the chi-squared test were used as appropriate. Multivariate logistic regression analyses were conducted. To summarize the serial clinical, serological, treatment and comorbidity measurements, areas under the curve were calculated by the trapezoid method and are presented standardized by the length of the study [26]. To identify baseline predictors of nonpersistence with medication, different models were constructed. At first, variables that were significant at $P<0.20$ on the univariate analysis were entered into the multivariate model (age, erythrocyte sedimentation rate and C-reactive protein). We also included in the final model the baseline variables reported in the literature to be associated with poor adherence/persistence: male sex, lower education, socioeconomic status, disability (baseline $\mathrm{HAQ}$ ), perceived health status (patient $100 \mathrm{~mm}$ visual analogue scale for overall disease activity) and comorbidity $[10,14-20,22,23]$ - although all of them showed $P>0.20$ in the univariate analysis. At the beginning, saturated models were tested and the less significant variables were excluded. 
Finally, the parsimonious models are reported. Two-tailed $P \leq$ 0.05 was considered significant. Analyses were performed using the SPSS/PC program (version 12.0; SPSS Inc., Chicago, IL, USA).

\section{Results}

\section{Persistence on medication survival function}

By March 2008 data from 75 patients had been analyzed and 935 notes reviewed. Of these, 860 notes were evaluated (75 baseline notes excluded) and 71 (8.3\%) notes with therapy discontinuation were identified; most of those notes $(80.3 \%)$ recorded that patients were nonpersistent with one DMARD 29 of them $(40.8 \%)$ with methotrexate, 23 patients $(32.4 \%)$ with chloroquine, 15 patients $(21.1 \%)$ with sulphasalazine, 11 patients (15.5\%) with penicillamine, eight patients $(11.3 \%)$ with leflunomide, six patients $(8.5 \%)$ with minocicline and one patient $(1.4 \%)$ with prednisone.

Forty-three patients (57.3\%) were nonpersistent on at least one evaluation and their (mean \pm standard deviation (SD)) days of therapy discontinuation were $41.7 \pm 25.9$. There were incident nonpersistent patients at each consecutive visit, their numbers ranging from one patient at visit 7 to seven patients at visit 4. Among nonpersistent patients, 24 (55.8\%) were nonpersistent at one evaluation and their (mean \pm SD) days of therapy discontinuation were $28.9 \pm 16.6$; 11 patients $(25.6 \%)$ were nonpersistent at two evaluations and accumulated (mean \pm SD) $47.6 \pm 21.5$ days of therapy discontinuation; seven patients (16.3\%) were nonpersistent at three evaluations and had (mean \pm SD) $65 \pm 22.4$ days of therapy discontinuation; and finally, one patient $(2.3 \%)$ was nonpersistent at four visits and his global period of therapy discontinuation was 119 days.

Figure 1 shows the cumulative risk of being persistent on therapy, which decreased from $98 \%$ at visit 2 (2.15 \pm 0.44 months of follow-up) to $34 \%$ at visit 13 (24.6 \pm 6.17 months of followup).

\section{Baseline characteristics of the population studied}

As shown in Table 1, baseline demographic and disease characteristics, comorbidities, baseline treatment and previous treatment (during the month previous to the baseline evaluation at the clinic) were the same in persistent patients and nonpersistent patients but the persistent patients were younger. Forty-eight percent of the patients from both groups had baseline positive antinuclear antibodies; fine and gross speckle were the most frequently reported patterns (68\%). The dose range of current use of corticosteroids at baseline evaluation was between 5 and $15 \mathrm{mg} /$ day (equivalent to oral prednisone).

Figure 1

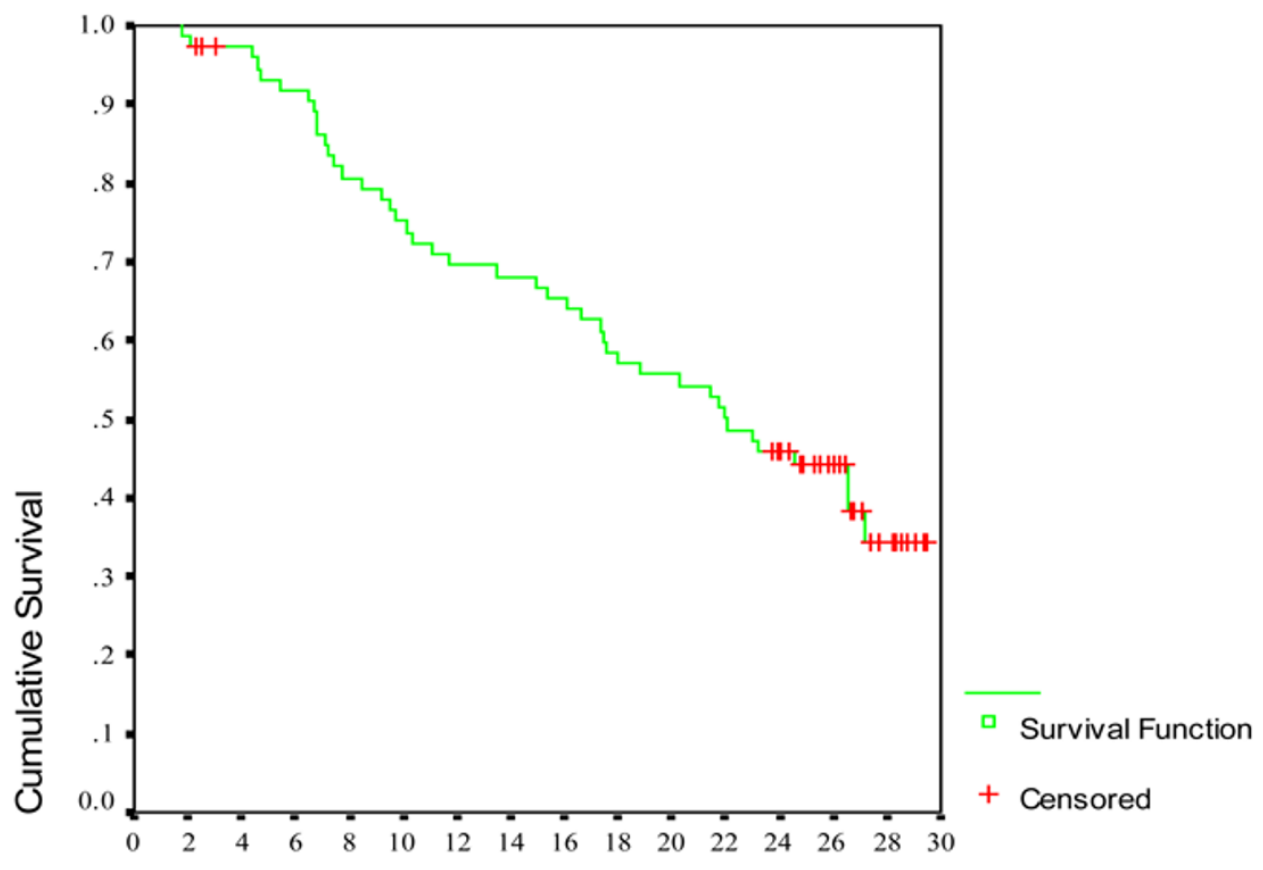

Months of follow-up

Cumulative risk of being persistent on therapy over 2 years of follow-up. Persistence decreased from $98 \%$ at visit $2(2.15 \pm 0.44$ months of followup) to $34 \%$ at visit 13 (24.6 \pm 6.17 months of follow-up). 


\begin{tabular}{|c|c|c|c|}
\hline Variable & Persistent-patients $(n=32)$ & Nonpersistent patients $(n=43)$ & $P$ value \\
\hline \multicolumn{4}{|l|}{ Socio-demographic? } \\
\hline Female sex (n (\%)) & $27(84.4 \%)$ & $36(83.7 \%)$ & 1 \\
\hline Age at baseline evaluation (years) & $36.1 \pm 12.6$ & $42.5 \pm 13.7$ & 0.04 \\
\hline Years of education & $10.2 \pm 3.6$ & $10.1 \pm 3.8$ & 0.90 \\
\hline Low socioeconomic status ( $(\%))$ & $27(84.4 \%)$ & $38(88.8 \%)$ & 0.87 \\
\hline Single $(\mathrm{n}(\%))$ & $17(53 \%)$ & $18(42 \%)$ & 0.36 \\
\hline \multicolumn{4}{|l|}{ Disease characteristics } \\
\hline Number of American College of Rheumatology criteria & $5.3 \pm 0.7$ & $5 \pm 1.2$ & 0.23 \\
\hline Time since first symptom (months) & $5.5 \pm 2.9$ & $5.2 \pm 2.7$ & 0.55 \\
\hline Disease activity score (28 joints) & $6.3 \pm 1.2$ & $6.2 \pm 1.3$ & 0.65 \\
\hline Health assessment questionnaire (0 to 3 ) & $1.5 \pm 0.8$ & $1.5 \pm 0.9$ & 0.91 \\
\hline $\begin{array}{l}\text { Physician global assessment of disease activity visual analogue } \\
\text { scale }(0 \text { to } 100)\end{array}$ & $49.1 \pm 23$ & $43.8 \pm 20.9$ & 0.30 \\
\hline Patient pain visual analogue scale (0 to 100$)$ & $60.4 \pm 24.8$ & $58.6 \pm 26$ & 0.76 \\
\hline Patient overall disease visual analogue scale (0 to 100 ) & $62.1 \pm 28$ & $61.1 \pm 26.4$ & 0.87 \\
\hline Erythrocyte sedimentation rate (mm/hour) & $36.6 \pm 26.8$ & $29.8 \pm 18.1$ & 0.19 \\
\hline C-reactive protein (mg/dl) & $3.4 \pm 5.1$ & $2.2 \pm 2.9$ & 0.17 \\
\hline Patients with rheumatoid factor $(\mathrm{n}(\%))$ & $23(71.9 \%)$ & $30(69.8 \%)$ & 1 \\
\hline Patients with antibodies to cyclic citrullinated peptides ( $(\%))$ & $22(68.8 \%)$ & $29(69 \%)^{a}$ & 1 \\
\hline Patients with comorbidity (n (\%)) & $12(38 \%)$ & $15(35 \%)$ & 1 \\
\hline \multicolumn{4}{|l|}{ Baseline treatment at the clinic } \\
\hline Corticosteroid use $(\mathrm{n}(\%))$ & $9(28.1 \%)$ & $11(25.6 \%)$ & 1 \\
\hline Number of DMARDs/patient & $2 \pm 0.7$ & $1.8 \pm 0.8$ & 0.36 \\
\hline Number of drugs for comorbid conditions/patient & $1.75 \pm 1.3$ & $1.4 \pm 0.8$ & 0.40 \\
\hline Number of total drugs/patient & $3.6 \pm 1.3$ & $3.4 \pm 1.2$ & 0.56 \\
\hline \multicolumn{4}{|l|}{ Previous treatment } \\
\hline Corticosteroid use (n (\%)) & $4(12.5 \%)$ & $9(29.9 \%)$ & 0.38 \\
\hline DMARD use (n (\%)) & $11(34.4 \%)$ & $12(27.9 \%)$ & 0.61 \\
\hline Number of DMARDs/patient (among users) & $1.5 \pm 0.5$ & $1.4 \pm 0.5$ & 0.86 \\
\hline
\end{tabular}

Data presented as the mean \pm standard deviation unless otherwise indicated. DMARD, disease-modifying antirheumatic drug. aOne missing data.

Relationship between persistence on medication and disease activity

Standardized areas under the curve (mean \pm SD) for clinical and serological (erythrocyte sedimentation rate and C-reactive protein) disease activities were similar between both groups, as were areas under the curve for the number of comorbidities/patient and the number of drugs/patient (Table 2).

Persistent patients had similar (mean \pm SD) DAS28 at baseline and at visits 2 and 3 to nonpersistent patients. After 6 months of follow-up, persistent patients had lower (mean \pm
SD) consecutive DAS28 than nonpersistent patients and the differences were statistically significant at visits 4 to 9 and at visit $13(P \leq 0.03)$, as shown in Figure 2. In addition, persistent patients had greater improvements in disease activity (measured by the difference between the DAS28 at the corresponding visit and the baseline DAS28) at every consecutive visit than nonpersistent patients; differences were statistically significant at visit 4 (3.5 \pm 1.5 versus $2.6 \pm 1.5, P=0.009)$, at visit $6(4.2 \pm 1.5$ versus $3.4 \pm 1.6, P=0.04)$, at visit $7(4.2 \pm$ 1.5 versus $3.4 \pm 1.6, P=0.04)$ and at visit $9(4.3 \pm 1.5$ versus $3.4 \pm 1.5, P=0.01)$. 
Table 2

Standardized AUCs for clinical, serological, comorbidity and treatment serial measurements of persistent and nonpersistent patients

\begin{tabular}{|c|c|c|c|}
\hline AUC for serial assessments & Persistent-patients $(n=32)$ & Nonpersistent patients $(n=43)$ & $P$ value \\
\hline \multicolumn{4}{|l|}{ Clinical } \\
\hline Disease activity score (28 joints) & $2.83 \pm 1.45$ & $3.04 \pm 0.89$ & 0.45 \\
\hline 66 swollen joint counts & $3.65 \pm 5.06$ & $3.99 \pm 2.86$ & 0.72 \\
\hline 68 tender joint counts & $4.02 \pm 5.16$ & $3.94 \pm 2.74$ & 0.94 \\
\hline $\begin{array}{l}\text { Physician global assessment of disease activity visual analogue } \\
\text { scale }\end{array}$ & $11.72 \pm 16.46$ & $12.24 \pm 7.60$ & 0.87 \\
\hline Patient pain visual analogue scale & $11.79 \pm 11.42$ & $12.77 \pm 7.24$ & 0.65 \\
\hline Patient overall disease visual analogue scale & $11.73 \pm 12.3$ & $13.19 \pm 7.26$ & 0.52 \\
\hline Health assessment questionnaire & $0.23 \pm 0.36$ & $0.36 \pm 0.32$ & 0.23 \\
\hline \multicolumn{4}{|l|}{ Serological } \\
\hline Erythrocyte sedimentation rate & $16.99 \pm 11.97$ & $15.99 \pm 9.67$ & 0.69 \\
\hline C-reactive protein & $1.18 \pm 1.52$ & $0.73 \pm 0.69$ & 0.13 \\
\hline Number of comorbidities/patient & $1.33 \pm 2.4$ & $1.1 \pm 1.48$ & 0.62 \\
\hline \multicolumn{4}{|l|}{ Treatment } \\
\hline Number of DMARDs/patient & $2.31 \pm 0.71$ & $2.47 \pm 0.71$ & 0.35 \\
\hline Number of drugs for comorbidity/patient & $1.81 \pm 1.03$ & $1.83 \pm 0.88$ & 0.90 \\
\hline Number of total drugs/patient & $4.38 \pm 1.13$ & $4.61 \pm 1.17$ & 0.39 \\
\hline
\end{tabular}

Data presented as the mean \pm standard deviation. AUC, area under the curve; DMARD, disease-modifying antirheumatic drug.

Sustained remission definition (at least three consecutive visits with DAS28 $<2.6$ ) required at least 6 months of follow-up. Seventy-two patients met the follow-up required: 70 patients completed 13 consecutive visits, one patient underwent seven consecutive visits and another patient completed 12 consecutive visits. More persistent patients had sustained remission at last follow-up than nonpersistent patients (24 (82.8\%) versus $20(46.5 \%)$ patients, $P=0.003)$. Among patients who achieved sustained remission, persistent patients had shorter follow-up to outcome than nonpersistent patients $(7.7 \pm 4.5$ versus $13.6 \pm 5.7$ months, $P=0.001$ ).

\section{Relationship between persistence on medication and disability}

Both groups of patients had similar standardized areas under the curve for the HAQ (Table 2). Persistent patients had similar baseline (mean $\pm \mathrm{SD}$ ) HAQ scores to nonpersistent patients. At each follow-up visit, persistent patients had lower (mean \pm SD) HAQ scores than nonpersistent patients and the differences were statistically significant at visit 3 , at visits 5 to 7 , and at visits 9, 10 and 13, as shown in Figure 3. Finally, persistent patients had shorter follow-up to the first visit with $\mathrm{HAQ}$ score $\leq 0.20$ than nonpersistent patients (mean \pm SD, $5.2 \pm 4$ versus $8.2 \pm 5.7$ months, $P=0.02$ ).

\section{Relationship between persistence on medication and erosive disease}

We compared persistence on medication between patients who did and who did not develop erosive disease according to radiography. One nonpersistent patient had erosive disease at baseline and was discarded from the analysis. Five additional patients did not complete the 2-year follow-up and did not have corresponding X-ray scans - their data were also excluded. Finally, 69 patients had X-ray scans performed at 2 years of follow-up: 28 were persistent and 41 were not. More nonpersistent patients developed erosive disease than persistent patients but the difference did not reach statistical significance (5 (17.9\%) versus $11(26.8 \%), P=0.56)$.

\section{Baseline factors associated with nonpersistence on medication}

In the multivariate model, among the 43 nonpersistent patients, older age was the only variable to be consistently associated with nonpersistence on therapy (odds ratio $=1.1$, $95 \%$ confidence interval $=1.007$ to $1.103, P=0.02$ ) and was still associated after controlling for early (during the first 12 months of follow-up) nonpersistence versus late (after 12 months of follow-up) nonpersistence. Similar results were obtained when the model was applied in the 24 patients who were nonpersistent at only one evaluation during their 2-year follow-up (older age, odds ratio $=1.04,95 \%$ confidence inter$\mathrm{val}=1.002$ to $1.087, P=0.04$ ). 


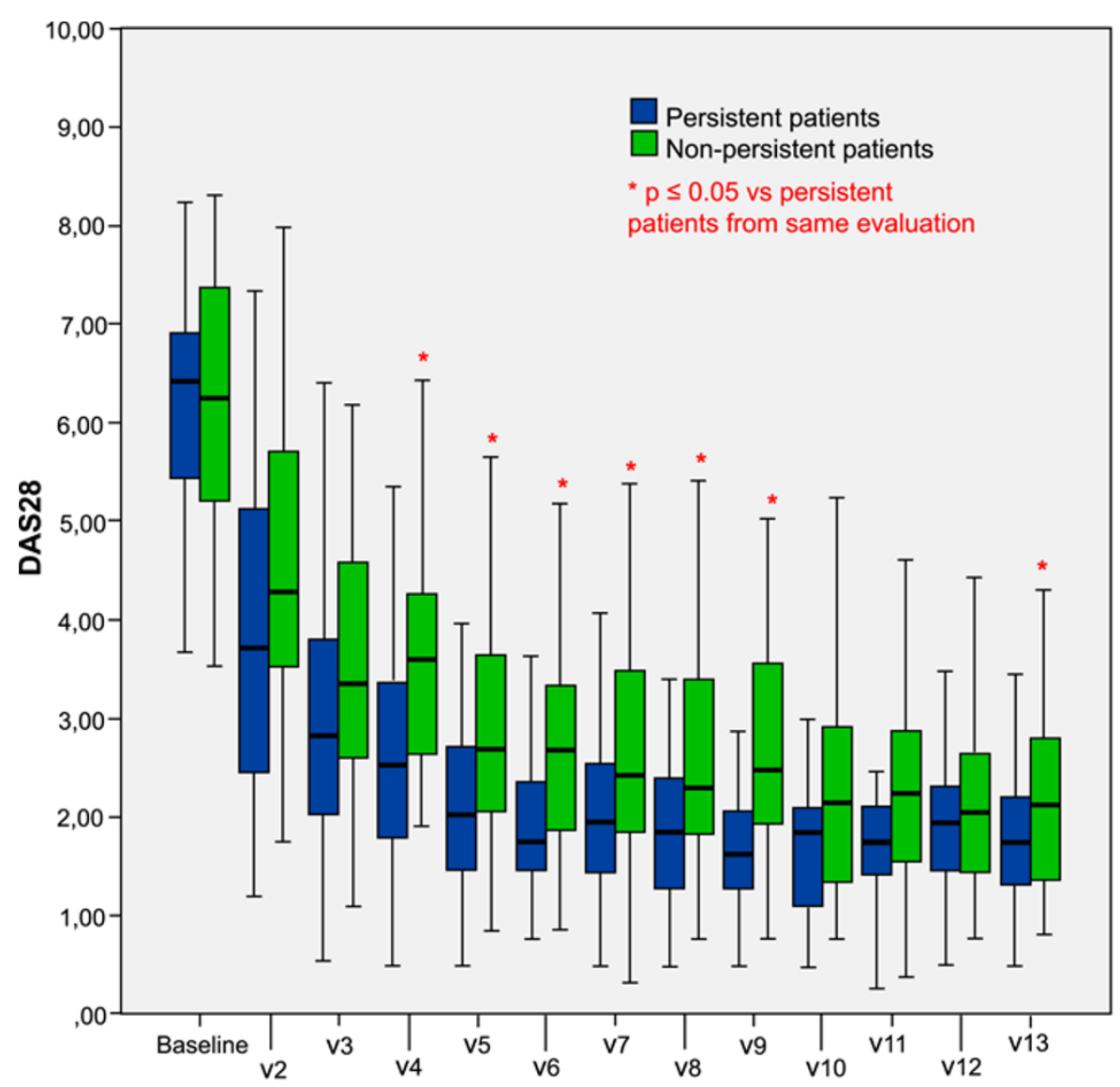

Persistent vs. Non-persistent patients (Mean \pm SD.) DAS 28: Baseline (6.3 \pm 1.2 vs. $6.2 \pm 1.3)$, V2 $(4.1 \pm 1.7$ vs. $4.5 \pm 1.4)$, V3 $(3 \pm 1.4$ vs. $3.3 \pm 1.3)$ V $4(2.7 \pm 1.2$ vs. $3.6 \pm 1.1)$, V5 $(2.2 \pm 1.1$ vs. $2.9 \pm 1.3)$ V6 $(2 \pm 0.9$ vs. $2.8 \pm 1.2)$, V7 $(1.9 \pm 0.9$ vs. $2.8 \pm 1.3)$, V $8(1.9 \pm 1$ vs. $2.6 \pm 1.2)$ V9 $(1.9 \pm 1.1$ vs. $2.8 \pm 1.2), \mathrm{V} 10(2 \pm 1.2$ vs. $2.2 \pm 1)$, V11 (1.9 \pm 1 vs. $2.4 \pm 1.2), \mathrm{V} 12(2 \pm 0.8$ vs. $2.1 \pm 0.9)$ and V13 $(1.7 \pm 0.7$ vs. $2.3 \pm 1.2)$

Comparison of consecutive 28-joint disease activity scores between persistent patients and nonpersistent patients. Consecutive 28-joint disease activity score (DAS28) for persistent patients (blue bars) and nonpersistent patients (green bars). Thick line in middle of bar, mean DAS28 value; top and bottom of bar, upper and lower quartiles, respectively; top and bottom lines, maximum and minimum values, respectively. $x$ axis, consecutive visits (V); $y$ axis, DAS28 values. *Differences with $P \leq 0.05$. SD, standard deviation.

\section{Discussion}

The terminology, definitions and methods to determine adherence and persistence differ greatly in the published literature [27]. A need for improvement in the quality and consistency of medication compliance and persistence research is mandatory. In 2006 the International Society of Pharmaeconomics and Outcomes Research published a consensus document that was intended to improve the consistency and quality of analysis regarding this topic and to understand the impact of compliance and adherence on health outcomes [28]. Two years later, Cramer and colleagues provided specific definitions for compliance and persistence, and encouraged their adoption by health outcome researchers [4]. In the present study we have adopted those definitions and analyzed persistence on DMARDs and corticosteroids in early RA patients. Nonetheless, poor adherence may be related to therapy dis- continuation (that is, nonpersistence according to the recent proposal) and most of the published studies do not include persistence as a separate construct from compliance, which makes difficult a comprehensive discussion on the topic.

The present study highlights the impact of therapy persistence on different RA outcomes. After 6 months of follow-up, persistent patients showed lower scores and greater improvements in disease activity and disability and had more frequent and earlier sustained remission than nonpersistent patients. It may be argued that it is not clear whether better outcomes were a cause of or an effect of persistence on therapy. Nonetheless, at initial evaluations both groups of patients had similar clinical status, demography (except age), comorbidities, and disease characteristics. Treatment at baseline and during follow-up did not differ between them, suggesting that greater clinical 


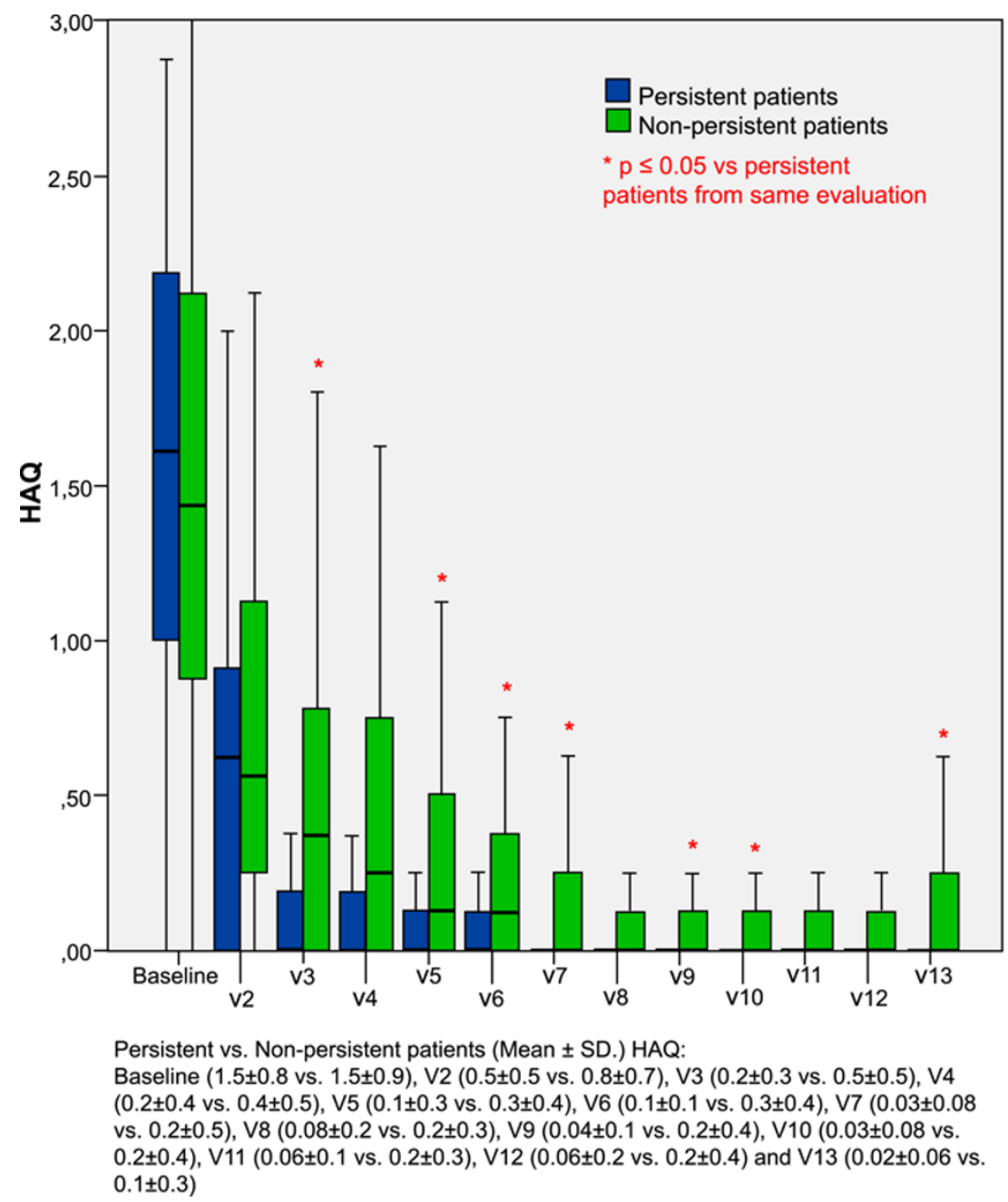

Comparison of consecutive health assessment questionnaire scores between persistent patients and nonpersistent patients. Consecutive health assessment questionnaire (HAQ) scores for persistent patients (blue bars) and nonpersistent patients (green bars). Thick line in middle of bar, mean value; top and bottom of bar, upper and lower quartiles, respectively; top and bottom lines, maximum and minimum values, respectively. $x$ axis, consecutive visits $(\mathrm{V})$; $y$ axis, $\mathrm{HAQ}$ values. ${ }^{*}$ Differences with $P \leq 0.05$. SD, standard deviation.

improvement in persistent patients was probably related to persistence on therapy. To the best of our knowledge there is only one study that has evaluated compliance and RA outcomes. Viller and colleagues showed more frequent improvement in disability (no relationship with disease activity was investigated) in consistently compliant European RA patients over 3 years of follow-up than in those who changed behavior [21]. They included 556 patients with $<5$ years of disease duration, and compliance with drug dosages and dosing times was assessed yearly using a questionnaire. We also found that more nonpersistent patients developed erosive disease than persistent patients, although the difference was not statistically significant - we were probably limited by the number of patients with erosive disease. Interestingly, most nonpersistent patients (56\%) omitted treatment once during follow-up; among them, the number of therapy-discontinuation days was low ( $4 \%$ of the indicated days of therapy) but impacted negatively on the disease prognosis.

Among potential candidates, older age was the only predictor to be associated with nonpersistence on DMARD and corticosteroid therapy. Kristensen and colleagues identified high age (in addition to low $\mathrm{C}$-reactive protein serum level, elevated $\mathrm{HAQ}$ score, and higher previous number of DMARDs) as a predictor of premature treatment termination (which may be considered a synonym for nonpersistence) with etarnecept and infliximab in 1,161 patients with active RA [29]. By contrast, Viller and colleagues found older age (in addition to female sex, decreased disability, very satisfactory contacts with health professionals, and more personal knowledge about the disease and its treatment) significantly associated with good compliance in their early RA cohort [20]. Self- 
reporting of current medication use with DMARDs (methotrexate, sulphasalazine, and corticosteroids) has been considered to have good to excellent agreement with information obtained from the medical charts [30]. In our study, the time between two visits was 2 months so the treatment recorded could be considered current treatment; meanwhile, compliance with drugs was assessed annually in the study of Viller and colleagues. Tuncay and colleagues performed three assessments for drug compliance over 1 year of follow-up in 100 RA patients [16]. Consistently compliant patients were older than consistently noncompliant patients, although no regression analysis was performed. In both studies, patients had longer disease duration than patients from our study and the concept of medication persistence as a different construct from medication adherence was not defined. Finally, Curkendall and colleagues showed that persistence on (and adherence with) anti-TNF $\alpha$ was better among older patients, in an inception cohort of anti-TNF $\alpha$-naïve-RA patients [23]; worse persistence was also associated with greater out-of-pocket costs, with higher Charlson's comorbidity score and with previous prescription for a narcotic analgesic. Adherence and persistence were measured using claims data on a particular RA population of unknown disease duration, which may have accounted for the different result.

Persistence on therapy decreased in our cohort of early RA patients up to $34 \%$ at 2 years of follow-up. Curkendall and colleagues showed that persistence on (and adherence with) anti-TNF $\alpha$ decreased over 1 year of follow-up in their inception cohort of RA patients, up to $32 \%$ in those patients with out-ofpockets costs above $\$ 50 /$ week [23]. Similar results were found regarding a decline of compliance by de Klerk and colleagues in 127 outpatients, 81 of whom had RA [10]; by Viller and colleagues, who identified $35.7 \%$ of consistently compliant patients after three years of follow-up [20]; and by Tunkay and colleagues, who found that $30.2 \%$ of 100 RA patients were consistently compliant over 1 year of follow-up [16]. Two other studies performed in 66 patients and 108 RA patients, respectively, showed higher rates of compliance and persistence with therapy, ranging from $61 \%$ to $73 \%[15,31]$. Numerous randomized clinical trials performed in RA patients had also assessed drug continuation (persistence) over different follow-up periods [32-38], although the probability of discontinuation for reasons other than adverse events and lack of efficacy was very low.

The present study has several limitations. We did not use a well-validated questionnaire scale to assess compliance/persistence $[11,13,39]$. We assessed persistence through the simplest and most used way in clinical practice, which is to ask the patient whether he/she is still taking the medication as prescribed [7,40-43]. We used a partially arbitrary and recently proposed definition to define nonpersistence. We choose a lag time of 1 week, as $89 \%$ of our patients were taken methotrexate and the drug is indicated weekly. We analyzed neither the whole spectrum of nonadherence/nonpersistence nor its repercussion on disease activity and damage - clinical outcomes of treatment are affected not only by how long patients take their medication but also by how well; accordingly, adherence should have been defined and measured to characterize medication-taking behavior comprehensively. In terms of guaranteeing a better prognosis, how to define a reasonable adherence/persistence is still unknown. Finally, the outcome is not the result of compliance and persistence alone but can be influenced by many other factors [44]. In that sense, the present study was carried out in an inception cohort of early RA patients, with particular sociodemographic characteristics, ethnicity, treatment and health system, and our results may not be generalized to RA populations with different characteristics [45].

In 2006, the American College of Rheumatology endorsed a starter set of quality indicators for several rheumatic diseases, among them RA $[46,47]$. Two measures pertinent to treatment were included and strategies proposed to be used when there is increased disease activity or damage progression over a 6month period. The recommendations add potential adverse events, increase costs, and are based on the assumption that patients are fully (or partially) compliant with therapy and persistent on medication. The present study reinforces the necessity to consistently investigate compliance and persistence with treatment before regimens are modified. Potential benefits are better prognosis, cost reductions and patient safety.

\section{Conclusion}

Nonpersistence on DMARDs was frequent and progressive over the first 2 years of follow-up in a cohort of early RA patients, a time frame that has been proposed as crucial for disease control/remission. Persistent patients were younger at baseline evaluation and had lower disease activity and disability during their follow-up than nonpersistent patients. Persistent patients reached sustained remission more frequently and earlier than nonpersistent patients. Persistence and adherence with medication should routinely be evaluated during RA follow-ups, especially at the beginning of the disease when adequate treatment has a major impact on disease outcomes.

\section{Competing interests}

The authors declare that they have no competing interests.

\section{Authors' contributions}

VP-R performed conception and design, data acquisition, analysis and interpretation of the data, drafting and critical review. IC-Y performed conception and design, data acquisition, and analysis and interpretation of the data. ARV-R performed analysis and interpretation of the data. JC performed data acquisition, and analysis and interpretation of the data. MR-G performed data acquisition, analysis and interpretation of the data and critical review. 


\section{References}

1. Wolfe F, Mitchell DM, Sibley JT, Fries JF, Bloch DA, Williams CA, Spitz PW, Haga M, Kleinheksel SM, Cathey MA: The mortality of rheumatoid arthritis. Arthritis Rheum 1994, 37:481-494.

2. Osterberg L, Blaschke T: Adherence to medication. $N$ Engl J Med 2005, 353:487-497.

3. Steiner JF, Earnest MA: The language of medication taking. Ann Intern Med 2000, 132:926-930.

4. Cramer JA, Roy A, Burrell A, Fairchild CJ, Fuldeore MJ, Ollendorf DA, Wong PK: Medication compliance and persistence terminology and definitions. Value Health 2008, 11:44-47.

5. Harrold LR, Andrade SE: Medication adherence of patients with selected rheumatic conditions: a systematic review of the literature. Semin Arthritis Rheum 2008 in press.

6. Walsh JC, Mandalia S, Gazzard BG: Responses to a month selfreport on adherence to antiretroviral therapy are consistent with electronic data and virological treatment outcome. AIDS 2002, 16:269-277.

7. Haynes RB, Taylor DW, Sackett DL, Gibson ES, Bernholz CD, Mukherjee J: Can simple clinical measurements detect patient noncompliance? Hypertension 1980, 2:757-764.

8. Cramer J, Rosenheck R, Kirk G, Krol W, Krystal J: Medication compliance feedback and monitoring in a clinical trial: predictors and outcomes. Value Health 2003, 6:566-573.

9. Haynes RB, McDonald HP, Garg AX: Helping patients follow prescribed treatment: clinical applications. JAMA 2002, 288:2880-2883.

10. de Klerk $E$, Heijde $D$ van der, Landewé $R$, Tempel $H$ van der, Urquhart J, Linden S van der: Patient compliance in rheumatoid arthritis, polymyalgia rheumatica, and gout. J Rheumato/ 2003, 30:44-54.

11. de Klerk E, Heijde $\mathrm{D}$ van der, Tempel $\mathrm{H}$ van der, Linden $\mathrm{S}$ van der: Development of a questionnaire to investigate patient compliance with antirheumatic drug therapy. J Rheumatol 1999, 26:2635-2641.

12. de Klerk E, Heijde $D$ van der, Tempel $H$ van der, Linden $S$ van der: The Compliance-Questionnaire-Rheumatology compared with electronic medication event monitoring: a validation study. J Rheumato/ 2003, 30:2469-2475.

13. Callahan LF, Brooks RH, Pincus T: Further analysis of learned helplessness in rheumatoid arthritis using a 'Rheumatology Attitudes Index'. J Rheumatol 1988, 15:418-426.

14. Gossec L, Tubach F, Dougados M, Ravaud P: Reporting of adherence to medication in recent randomized controlled trials of 6 chronic diseases: a systematic literature review. $A m ~ J$ Med Sci 2007, 334:248-254.

15. Deyo RA, Inui TS, Sullivan B: Noncompliance with arthritis drugs: magnitude, correlates, and clinical implications. J Rheumatol 1981, 8:931-936.

16. Tuncay R, Eksioglu E, Cakir B, Gurcay E, Cakci A: Factors affecting drug treatment compliance in patients with rheumatoid arthritis. Rheumatol Int 2007, 27:743-746.

17. García-González A, Richardson M, García Popa-Lisseanu M, Cox V, Kallen MA, Janssen N, Ng B, Marcus DM, Reveille JD, SuárezAlmazor ME: Treatment adherence in patients with rheumatoid arthritis and systemic lupus erythematosus. Clin Rheumatol 2008, 27:883-889.

18. Lorish $C D$, Richards $B$, Brown $S$ : Missed medication doses in rheumatic arthritis patients: intentional and unintentional reasons. Arthritis Care Res 1989, 2:3-9.

19. Lorish CD, Richards B, Brown S: Perspective of the patient with rheumatoid arthritis on issues related to missed medication. Arthritis Care Res 1990, 3:78-84.

20. Viller F, Guillemin F, Briancon S, Moum T, Suurmeijer T, Heuvel W van den: Compliance to drug treatment of patients with rheumatoid arthritis: a 3 year longitudinal study. J Rheumatol 1999, 26:2114-2122.

21. Viller F, Guillemin F, Briançon S, Moum T, Suurmeijer T, Heuvel W van den: Compliance with drug therapy in rheumatoid arthritis. A longitudinal European study. Joint Bone Spine 2000, 67:178-182.

22. Grijalva CG, Chung CP, Arbogast PG, Stein CM, Mitchel EF Jr, Griffin MR: Assessment of adherence to and persistence on disease-modifying antirheumatic drugs (DMARDs) in patients with rheumatoid arthritis. Med Care 2007, 45:S66-S76.
23. Curkendall S, Patel V, Gleeson M, Campbell RS, Zagari M, Dubois $\mathrm{R}$ : Compliance with biologic therapies for rheumatoid arthritis: do patients out-of-pocket payments matter? Arthritis Rheum 2008, 59:1519-1526.

24. Ramey DR, Raynauld JP, Fries JF: The health assessment questionnaire 1992; status and review. Arthritis Care Res 1992, 5:119-129.

25. Prevoo ML, van't Hof MA, Kuper HH, VAN Leeuwen MA, Putte LB van de, van Riel PL: Modified disease activity score that include twenty-eight-joint counts: development and validation in a prospective longitudinal study of patients with rheumatoid arthritis. Arthritis Rheum 1995, 38:44-48.

26. Matthews JN, Altman DG, Campbell MJ, Royston P: Analysis of serial measurement in medical research. BMJ 1990, 300:230-235.

27. Andrade SE, Kahler KH, Frech F, Chan KA: Methods for evaluation of medication adherence and persistence using automated databases. Pharmacoepidemiol Drug Saf 2006, 15:565-575

28. Peterson AM, Nau DP, Cramer JA, Benner J, Gwadry-Sridhar F, Nichol M: A checklist for medication compliance and persistence studies using retrospective databases. Value Health 2007, 10:3-12.

29. Kristensen LE, Saxne T, Nilsson J-A, Geborek P: Impact of concomitant DMARD therapy on adherence to treatment with etarnecept and infliximab in rheumatoid arthritis. Results from a six-year observational study in Southern Sweden. Arthritis Res Ther 2006, 8:R174.

30. Solomon DH, Stedman M, Licari A, Weinblatt ME, Maher N, Shadick N: Agreement between patient report and medical record review for medications used for rheumatoid arthritis: the accuracy of self-reported medication information in patient registries. Arthritis Rheum 2007, 57:234-239.

31. Lee $P, \operatorname{Tan} L J$ : Drug compliance in outpatients with rheumatoid arthritis. Aust NZ J Med 1979, 9:274-277.

32. Zink A, Listing J, Kary S, Ramlau P, Stoyanova-Scholz M, Babinsky K, von Hinueber U, Gromnica-Ihle E, Wassenberg S, Antoni C, Herzer P, Kekow J, Schneider M, Rau R: Treatment continuation in patients receiving biological agents or conventional DMARD therapy. Ann Rheum Dis 2005, 64:1274-1279.

33. Lipsky PE, Heijde DM van der, St Clair EW, Furst DE, Breedveld FC, Kalden JR, Smolen JS, Weisman M, Emery P, Feldmann M, Harriman GR, Maini RN: Infliximab and methotrexate in the treatment of rheumatoid arthritis. Anti-Tumor Necrosis Factor Trial in Rheumatoid Arthritis with Concomitant Therapy Study Group. N Engl J Med 2000, 343:1594-1602.

34. Hoekstra M, Laar MA van de, Bernelot Moens HJ, Kruijsen MW, Haagsma CJ: Longterm observational study of methotrexate use in a Dutch cohort of 1022 patients with rheumatoid arthritis. J Rheumato/ 2003, 30:2325-2329.

35. Klareskog L, van der HD, de Jager JP, Gough A, Kalden J, Malaise M, Martin Mola E, Pavelka K, Sany J, Settas L, Wajdula J, Pedersen $R$, Fatenejad S, Sanda M: Therapeutic effect of the combination of etarnecept and methotrexate compared with each treatment alone in patients with rheumatoid arthritis: double-blind randomized controlled trial. Lancet 2004, 363:675-681.

36. Cohen S, Hurd E, Cush J, Schiff M, Weinblatt ME, Moreland LW, Kremer J, Bear MB, Rich WJ, McCabe D: Treatment of rheumatoid arthritis with anakinra, a recombinant human interleukin1 antagonist, in combination with methotrexate: results of a twenty-four-week, multicenter, randomized, double-blind, placebo-controlled trial. Arthritis Rheum 2002, 46:614-624.

37. Dougados M, Emery P, Lemmel EM, de la Serna R, Zerbini CA Brin S, van Riel P: Efficacy and safety of leflunomide and predisposing factors for treatment response in patients with active rheumatoid arthritis: RELIEF 6 months data. Rheumatol 2003, 30:2572-2579.

38. Kremer JM, Genovese MC, Cannon GW, Caldwell JR, Cush JJ, Furst DE, Luggen ME, Keystone E, Weisman MH, Bensen WM, Kaine JL, Ruderman FM, Coleman P, Curtis DL, Kopp EJ, Kantor SM, Waltuck J, Lindsley HB, Markenson JA, Strand V, Crawfor B, Fernando I, Simpson K, Bathon JM: Concomitant leflunomide therapy in patients with active rheumatoid arthritis despite stable doses of methotrexate. A randomized, double-blind, placebo-controlled trial. Ann Intern Med 2002, 137:726-733.

39. Kristensen LE, Saxne T, Geborek P: The LUNDEX, a new index of drug efficacy in clinical practice: results of a five-year 
observational study of treatment with infliximab and etarnecept among rheumatoid arthritis patients in southern Sweden. Arthritis Rheum 2006, 54:600-606.

40. Stephenson BJ, Rowe BH, Haynes RB, Macharia WM, Leon G: The rational clinical examination. Is this patient taking the treatment as prescribed? JAMA 1993, 269:2779-2781.

41. Elliot WJ: Compliance strategies. Curr Opin Nephrol Hypertens 1994, 3:271-278.

42. Roter DL, Hall JA, Merisca R, Nordstrom B, Cretin D, Svarstad B: Effectiveness of interventions to improve patient compliance: a meta-analysis. Med Care 1998, 36:1138-1161.

43. Myers LB, Midence K: Concepts and issues in adherence. In Adherence to Treatment in Medical Conditions Edited by: Myers LB, Midence K. Amsterdam: Harwood Academic; 1998:3-18.

44. Tarlov AR, Ware JE, Greenfield S, Nelson EC, Perrin E, Zubkokk $\mathrm{M}$ : The medical outcomes study. An application of methods for monitoring the results of medical care. JAMA 1989, 262:925-930.

45. Mody GM, Cardiel MH: Challenges in the management of rheumatoid arthritis in developing countries. Best Pract Res Clin Rheumatol 2008, 22:621-641.

46. National Committee for Quality Assurance: HEDIS 2006 Technical Specifications: Disease Modifying Anti-rheumatic Drug Therapy in Rheumatoid Arthritis Washington, DC: National Committee for Quality Assurance; 2005.

47. Kahn KL, Mclean CH, Wong AL, Rubenstein LZ, Liu H, Fitzpatrick DM, Harker JO, Chen WP, Traina SB, Mittman BS, Hahn BH, Paulus HE: Assessment of American College of Rheumatology quality criteria for rheumatoid arthritis in a pre-quality criteria patient cohort. Arthritis Rheum 2007, 57:707-715. 